\title{
Abundance and Diversity of Sea cucumbers in Point Pedro Coastal Waters in Jaffna Peninsula of Sri Lanka
}

\author{
K. Veronika ${ }^{*}$, U. Edrisinghe ${ }^{1}$, K. Sivashanthini ${ }^{2}$ and A.R.S.B Athauda ${ }^{1}$ \\ Postgraduate Institute of Agriculture \\ University of Peradeniya \\ Sri Lanka
}

\begin{abstract}
Sea cucumbers are fascinating and commercially valuable species belong to Class Holothuroidea. The present study was conducted with the aim of documenting the species composition and diversity of sea cucumber population in Point Pedro coastal area of Jaffna peninsula. The investigation was carried out from May 2014 to June 2015 at two study sites namely Viyaparimuli and Munnai. Sea cucumbers were collected within random transects areas of $4 \mathrm{~m}$ width and $100 \mathrm{~m}$ length. All the sea cucumbers were brought to the laboratory and identified up to species level based on the morphological characters and spicule preparation. Standard ecological parameters such as Simpson's Index (D), Shannon index $(H)$ and Evenness index $(J)$ were estimated. A total of four species belong to the Order Aspidochirotida and two each representing Family Holothuriidae and Family Stichopodidae were identified. Among them Holoturiaatra was the dominant species contributing $46.46 \%$ of the population followed by $\underline{S}$. horrens, $\underline{S}$. herrmanni, $\underline{H}$. leucospilota representing $32.78 \%$, $17.16 \%$ and $3.60 \%$, respectively. The presence of $\underline{S}$. horrens, $\underline{S}$. herrmanni, $\underline{H}$. leucospilota were recorded for the first time in Point Pedro area. According to diversity indices, maximum species diversity, richness and evenness were reported at Munnai site compared to Viyaparimoolai site. The information and observations in this study will be of use in formulating management policies for the sea cucumber fishery in the Point Pedro coastal area.
\end{abstract}

Keywords: Coastal waters, diversity indices, sea cucumber, species composition

\section{INTRODUCTION}

Sea cucumbers (Class Holothuroidea) are a highly diverse group of marine invertebrates. They are found in many marine habitats such as with corals, sea grass beds, rocks, muddy and sandy flats. Sea cucumbers are distributed from shore to the greatest depths. However, they are most common in the Indian Ocean and the South West Pacific (Conad, 1990). According to James (2001), over 1000 species have been identified belong to six orders and 25 families worldwide. Several Asian Communities consume sea cucumbers either raw or in processed form (Conad, 1990). Besides the chemical constitutions, sea cucumbers show antiviral, antitumoral, anticancerous and antifertility properties and find useful in pharmaceutical industry (Conad, 1998).

\footnotetext{
Department of Animal Science, Faculty of Agriculture, University of Peradeniya, Sri Lanka

Department of Fisheries, Faculty of Science, University of Jaffna, Sri Lanka

Corresponding author: kveronika.8@gmail.com
} 
Processed Holothurians, Beach-de-mer is the major commodity in coastal as well as off shore fisheries in Sri Lanka. Sea cucumber fishery is principally confined to the Northwestern coast and Eastern coastal waters of Sri Lanka, and considered as the major sea cucumber fishing areas since it has been introduced to Sri Lanka (Dissanayaka et al, 2010). However sea cucumber fishery is not well established in coastal waters of Point Pedro due to the abundance of other low commercially valuable species. Beche-de-mer was in demand in these coastal waters during last few years when trade existed between Sri Lanka and China. Thus, small scale fishermen harvested sea cucumber by hand picking and by bottom set gill nets and sold to sea cucumber retailers occasionally. So far there are no records on diversity and abundance of sea cucumber species in Point Pedro coastal waters of Sri Lanka, where sea cucumber fishery is open access and unregulated. Hence, local fishers have increased their fishing effort during off season in major fishing areas of the country. Further, this fishery has led to reduction of fishing pressure on commercially valuable species to some extent.

Twenty four species of sea cucumbers have been recorded from Northwestern and Eastern parts of Sri Lanka by Dissanayaka and Athukorala (2008), whereas, Kuganathan (2014) has reported sixteen species of sea cucumbers in Jaffna estuary. However, prominent sand dunes, barrier beaches, fringing coral reefs lie along the Point Pedro area make it a unique coastline which provides habitats for distinct littoral fauna and flora (Rajasuriya and Premaratne, 2000). Hence, the present study was undertaken to identify the sea cucumber species and to estimate their species composition in Point Pedro coastal area in Jaffna, Sri Lanka.

\section{MATERIALS AND METHODS}

\section{Collection of samples}

This study was carried out during the period from May 2014 to June 2015. Two study sites were selected viz., Viyaparimulai (N 949.912' E 80¹3.517') and Munnai (N 0949.659'E $80^{\circ} 14.889^{\prime}$ ) (Fig. 1). Transects of $4 \mathrm{~m}$ width and $100 \mathrm{~m}$ length were made by direct visual assessment method on a monthly basis for the estimation of density and diversity of species at the two stations. using six replicates. Each transect was separated by a minimum distance of $5 \mathrm{~m}$ and data collections were carried out during low tide time only. The data obtained through the study were analysed with several diversity indices such as species richness, abundance, Shannon index and the Evenness index using PAST Software version 2.17c.

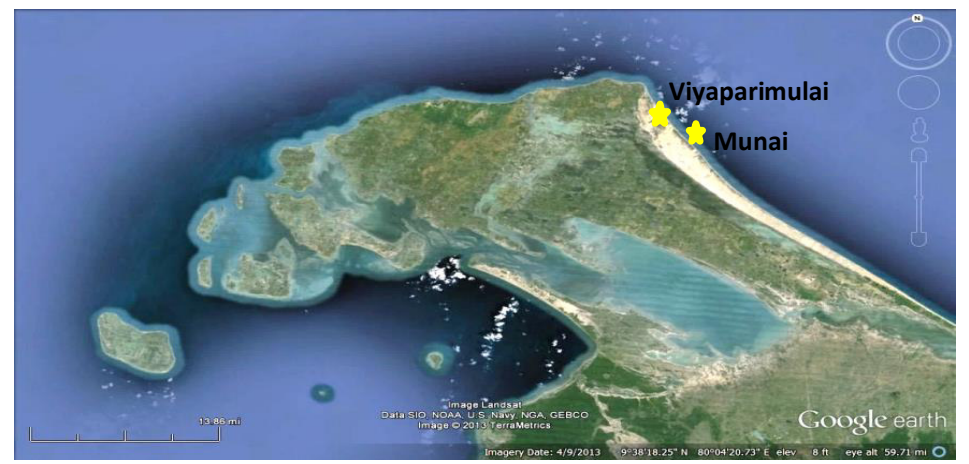

Fig. 1. Location of the study sites in coastal areas of Point Pedro Sample identification 
Samples were identified based on external characters such as body colour, types of tentacle and the presence or absence of Cuvierian tubules (Conand, 1998). In addition, taxonomic classification key was used as a guide for species identification (Clark and Rowe, 1971; Conand, 1990).Further, identification of sea cucumber up to species level was carried out by spicule preparation and the shape of the calcareous ring (Hickman, 1998; Veronica, 2005). Spicules were extracted from the flesh of the specimen by adding a saturated solution of sodium hypochlorite (Veronica, 2006). The calcareous ring was taken out from the oral region of each individual for examination, and spicules were examined using a compound microscope. Identified specimens were preserved in the laboratory of the Department of Fisheries, University of Jaffna.

\section{RESULTS AND DISCUSSION}

The present study identified a total of four species of sea cucumber, and out of which two species belonged to Family Holothuriidae and other two to Family Stichopodidae of Order Aspidochirotida. Among them Holothuria leucospilota, Stichopus horrens and Stichopus herrmanni were reported for the first time in Point Pedro coastal waters of Jaffna. Holoturia atra, Holothuria leucospilota, Stichopus horrens, Stichopus herrmanni(Fig. 2 to 5) were found in both study sites while $S$. horrens and $S$ herrmanni were found only in Munnai.

\section{Systematic position}

Species: Holoturia atra (Jaeger, 1833)

Phylum: Echinodermata

Subphylum: Echinozoa

Class: Holothuroidea

Order: Aspidochirotida

Family: Holothuriidae

Genus: Holoturia

\section{Commercial value:}

Low value for processed product.

\section{Diagnostic characters:}

Fig. 2 shows the details of $H$. atra, which has a sausage shaped body with rounded ends. Its skin is uniformly black, which is often covered with a fine coating of sand. A red fluid stain will appears when the body surface of live specimen is rubbed. Podia are sparsely distributed, but it is numerous on the ventral side. Characteristics of calcareous ring align with large radial pieces and narrow interradials. Ventral mouth is surrounded by 20 black peltate type tentacles and anus is terminal. Cuvierian tubules are absent. 


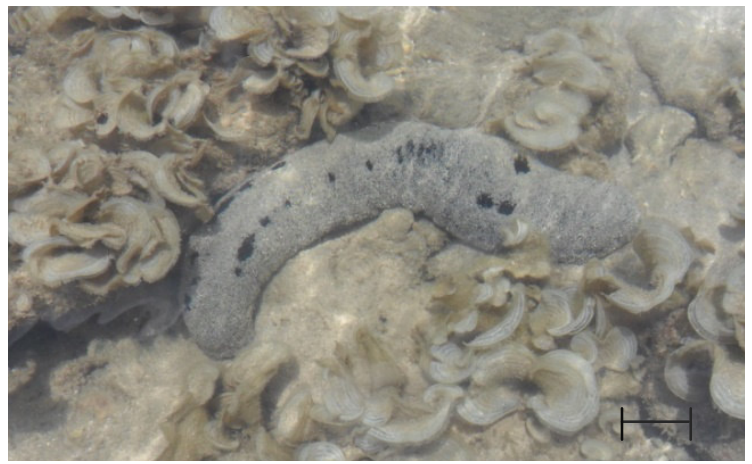

Fig. 2. Holoturiaatra

\section{Spicules}

Tables and rosettes are more abundant in dorsal and ventral body wall. Rods are absent in ventral podia but consists of pseudo plates. Simple slender rods are present in tentacles.

\section{Habitat characteristics}

This species is densely distributed in shallow water areas. It also lies on inner and outer reef flats. Mostly abundant on sandy grounds with coral rubbles and it prefers to live in calcareous algae and sea grass beds.

\section{Species: Holothuria leucospilota (Brandt, 1835)}

Commercial value: Low vaiued species

\section{Diagnostic characters}

Fig. 3 depicts the important morphological features of $H$. leucospilota. The features include elongated and snake like body. It is usually black in colour with randomly distributed long podia and papillae on the dorsal surface. Mouth is ventral with 20 large black tentacles. This sea cucumber species has a peculiar habitat of sticking its posterior end under the stone. When it is disturbed, this animal ejects thin Cuvierian tubules. Calcareous ring has characteristic large radial pieces with triangular interradials.

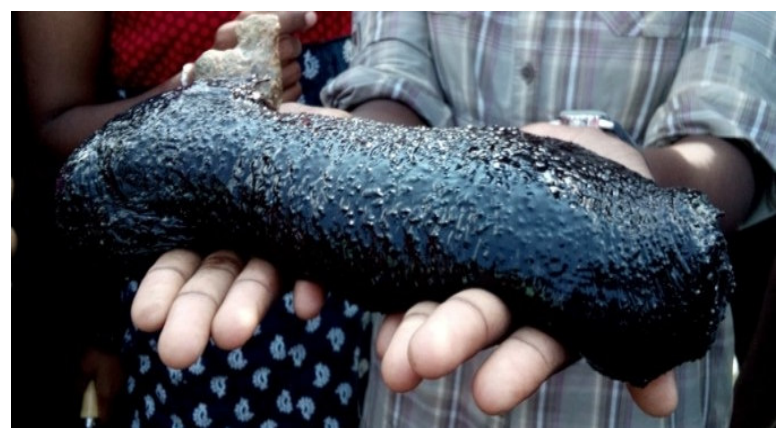

Fig.3. Holothurialeucospilota 


\section{Spicules}

Dorsal and ventral body wall has similar buttons and circular disc shaped tubules. Spicules are absent on tentacles.

\section{Habitat characteristics}

This species lives in shallow waters within the depth of $10 \mathrm{~m}$ and mostly found on outer and inner reef flats. It is commonly abundant on sandy bottoms with coral rubbles.

Family: Stichopodidae

Genus: Stichopus

\section{Species: Stichopus horrens(Selenka, 1867)}

Commercial value: Low commercial value for processed product.

\section{Diagnostic characters}

Colour of S. horrens is grey with greenish white (Fig. 4). Upper dorsal surface is covered with wart like papillae in two rows. Large podia occur along the lateral line of ventral surface. Ventral mouth is surrounded by half rows of papillae, and contains 18 green tentacles. Cuvierian tubules are absent and calcareous ring is characterised by triangular interradials.

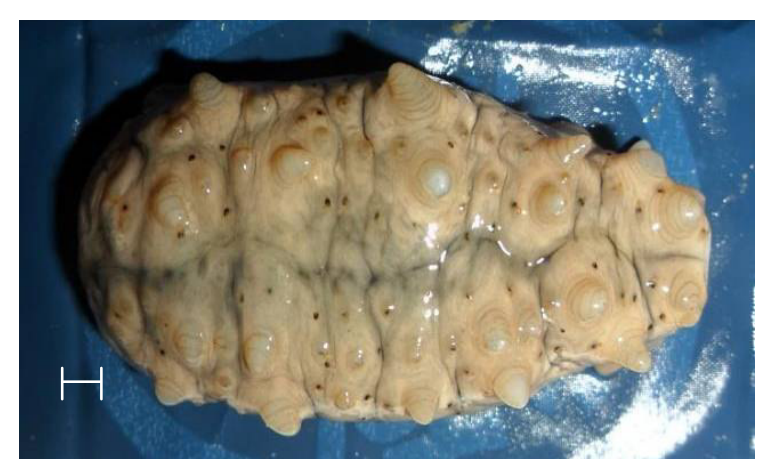

Fig. 4. Stichopushorrens

\section{Spicules}

Tentacles contain rod shaped spicules and it is forked or perforated distally. Dorsal and ventral body wall with numerous circular disc shaped tubules, characteristic X- shaped rosettes and a few C- shaped rods. Ventral podia consist of large perforated plates and tubules.

\section{Habitat characteristics}

This species is mostly found on rocky bottoms and reef flats. 


\section{Species: Stichopus herrmanni(Semper, 1868)}

Commercial value: Commercial value varies from low to medium for processed products.

\section{Diagnostic characters}

The detail photograph of $S$. herrmanni is given in Fig. 5. The distinguishable characters of the species include light mustard yellow colour body with numerous dark brown spots scattered all over the entire body. Podia are more prominent ventrally. Mouth is ventral which is surrounded by a circle of conical papillae and 20 brown tentacles. When the animal is out of sea water the body wall disintegrates after a few hours. Cuvierian tubules are absent. Calcareous ring characterised by deeply indented radial pieces and small interradials.

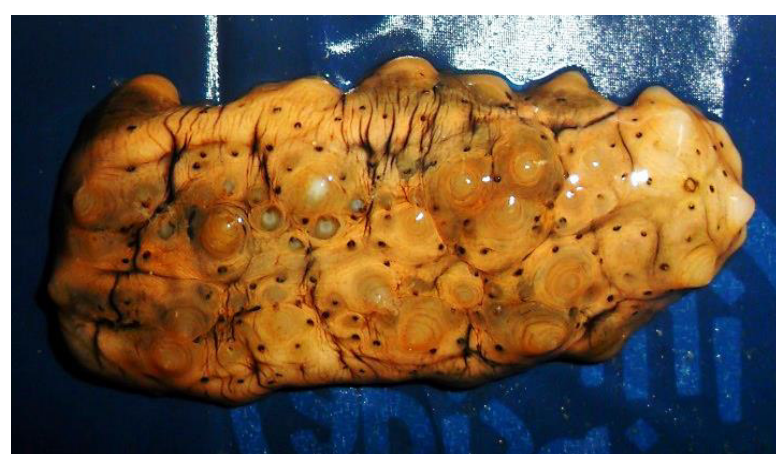

Fig. 5. Stichopusherrmanni

\section{Spicules}

Dorsal and ventral body wall with undulated disc shaped tubules, C or S- shaped rods and cross shaped rosettes.

\section{Habitat characteristics}

They occur on sea grass beds, coral reefs and on clean sandy bottoms.

Species wise sea cucumber composition at Point Pedro coastal waters showed that Holoturiaatra is the dominant species contributing $46.46 \%$ of the population, followed by Stichopus horrens, Stichopus herrmanni, Holothuria leucospilota consisting 32.78\%, $17.16 \%$ and 3.6\% respectively (Fig.6). The highest Pielou's Evenness (J) (0.8283), and the maximum Shannon Wiener's diversity $(\mathrm{H})$ (1.148) observed in Munnai were compared to Viyaparimoolai (0.2559). Simpson species index (D) was greater in Munnai (0.6578) than in Viyaparimoolai (0.1317) (Fig. 7). Based on these data, maximum species diversity, richness and evenness were reported in Munnai study site compared to Viyaparimoolai study site. 


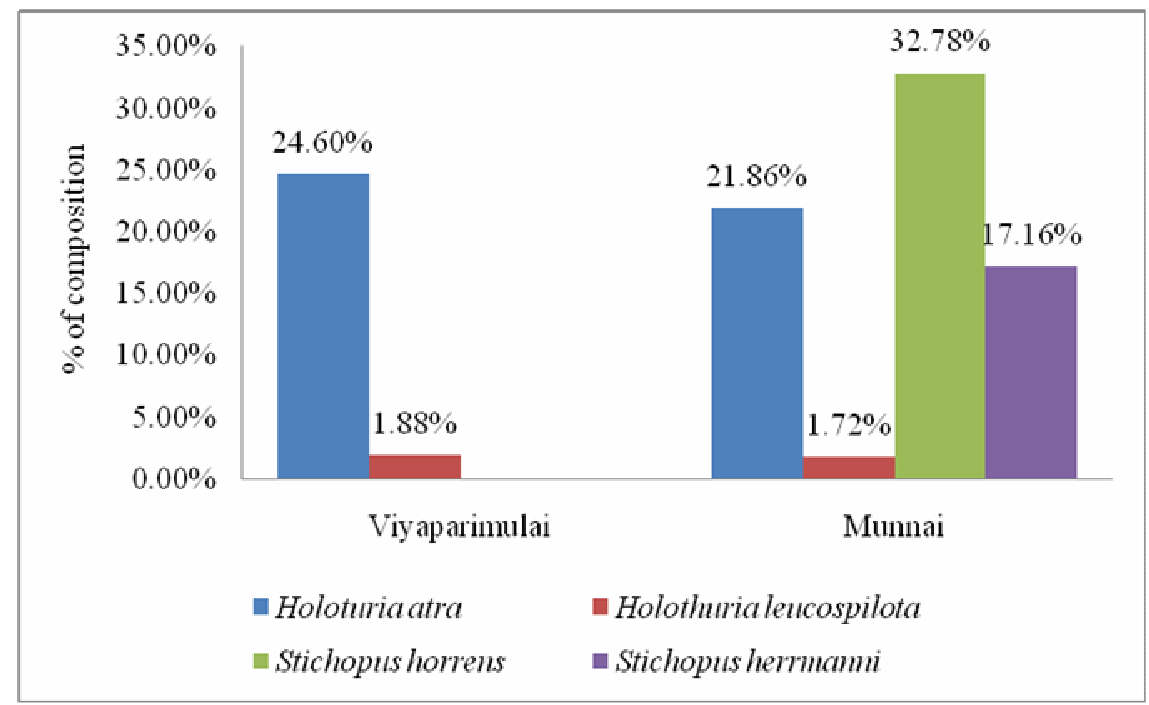

Fig. 6. Percentage of species composition of Holothurians in Point Pedro coastal waters

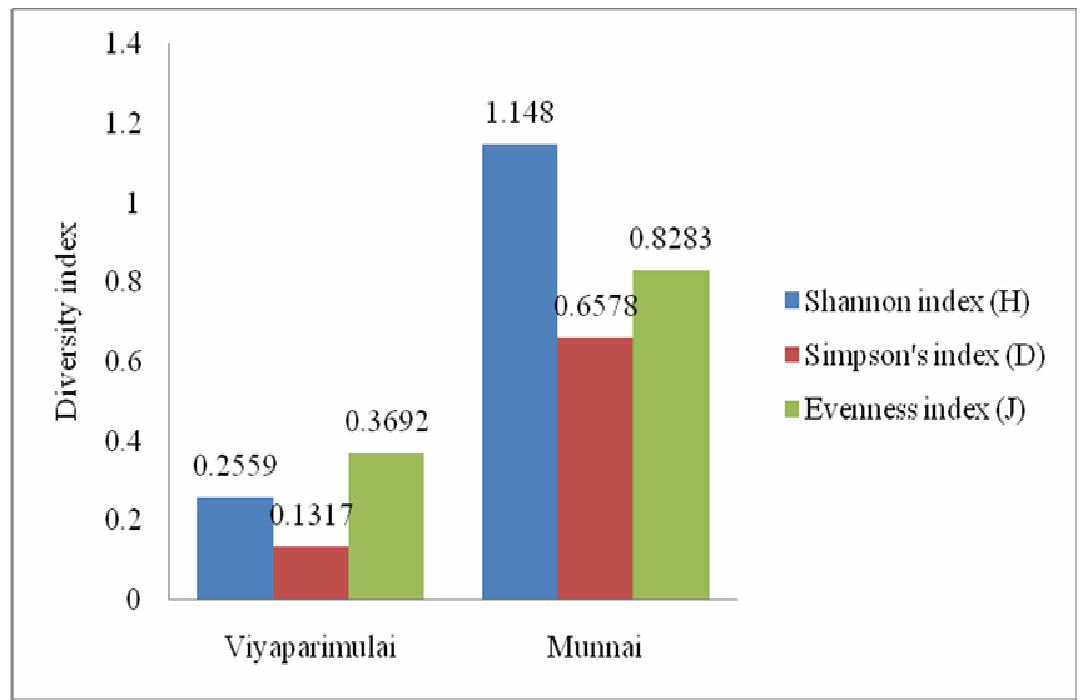

Fig. 7. Diversity Indices of Holothurian species at Point Pedro.

\section{CONCLUSIONS}

Four species (Holoturia atra, Holothuria leucospilota, Stichopus horrens, Stichopus herrmanni) were found in Point Pedro Coastal Area during the present study. Out of the four species recorded here, Holoturia atra has already been reported as plentiful in coastal areas of Point Pedro (Mageswaran and Vaseetha, 1985). The occurrence of Holothuria leucospilota, Stichopus horrens and Stichopus herrmanni were recorded for the first time in 
Point Pedro Coastal waters in Jaffna Peninsula. In depth studies on ecological and biological of sea cucumbers are necessary to investigate the factors which influence the pattern of distribution of these species and to implement appropriate management strategies to the existing species.

\section{REFERENCES}

Conad, C. (1990). The fishery resources of Pacific Island countries: Holohturians. FAOFisheries Technical Paper. 272.

Conad, C. (1998). The marine living resources of the Western Central Pacific.pp. 1157 1190. In: Carpenter. K. and Niem.V. (Ed.) FAO species identification guide.FAO. Rome.

Clark, A.M. and Rowe, F.W.E. (1971). Monograph of Shallow Water Indo-West Pacific echinoderms. Nat. Hist. 1 - 234.

Dissanayake, D.C.T. and Athukorala, S. (2008).Status and Management of Sea Cucumber Fishery in Sri Lanka.10 - 12.

Dissanayake, D.C.T., Athukorala, S. and Amarasiri, C. (2010). Present status of the sea cucumber fishery in Sri Lanka. SPC Beche-de-mer Information Bulletin 30, 14 - 20.

Hickman, C.J. (1998). A field guide to sea stars and other echinoderms of Galapagos. Sugar Spring Press. 83.

James, D.B. (2001). Twenty sea cucumbers from seas around India.Naga.The ICLARM Quarterly.24, 4 - 8.

Kuganathan, S. (2014). Sea cucumbers: Status and culture potential in the Jaffna Lagoon, Sri Lanka.Harikanan (Pvt) Ltd., Jaffna, Sri Lanka.

Rajasuriya, A. and Premaratne, A. (2000). Seas in the Millenium: An Environmental Evaluation. Elsivier Science. 175 - 187.

Mageswaran, R and Vaseetha, B. (1985). Chemical constituents of some species of holothurians found in Sri Lanka. Journal of the National Science Council of Sri Lanaka.13(2), 115 - 130.

Veronica, T. G. M. (2006). Fact sheets and identification guide for commercial sea cucumber species.SPC Beche-de-mer Information Bulletin.24, 49 - 52.

Veronica, T.G.M. (2005). The use of calcareous spicules for the identification of the Galapagos sea cucumberIsostichopusfuscus on the international market. SPC Beche-de-mer Information Bulletin. 22, 3 - 5. 